\title{
Examining the Role of Senior Nursing Leadership Requirements in Emergency Medical Centers
}

\author{
Prof Dr Paul James \\ Graduate School, Bangkok University \\ Klong-Toey, Rama 4 Road, Bangkok 10110 \\ Tel: 66-23-503-500Ｅ-mail: paul.j@bu.ac.th
}

Received: April 6, $2020 \quad$ Accepted: June 16, $2020 \quad$ Published: July 1, 2020

doi:10.5296/jmr.v12i3.17056 URL: https://doi.org/10.5296/jmr.v12i3.17056

\begin{abstract}
This is a research paper that is focused on the evaluation of senior nursing leadership perceptions and its impacts on Emergency Medical Centre (EMC) practices and developments related to private hospital provision in Bangkok.

An interpretive methodology was utilised in order to help understand senior nurses' perceptions underpinning nursing leadership. The scope for this research were EMC teams. The population of interest was made up of 13 senior nurses, encompassing single-site private hospitals in Bangkok. Ten (10) senior-level nursing practitioners at Emergency Trauma Centres were carefully targeted as a resultant sample size.

The research outcomes consisted of three (3) Main Themes - Individual Nursing Characteristics; System Qualities; Work Features and ten (10) sub-themes - with 248 dialogue targets.

The paper addresses a number of raised areas resulting out of the analysis of the narrative to ascertain implications for managing senior nursing leadership requirements within the EMC of private hospitals and addresses hospital concerns/responses and managerial difficulties related to developing opportunities for senior nurse leadership in private hospital EMCs.
\end{abstract}

Keywords: Nursing Leadership, Emergency Centre, Private Hospitals, Bangkok 


\section{Introduction}

2020, Vol. 12, No. 3

Emergency medical services encompasses the systematic management of medical-related emergencies that occur outside a hospital (Mistovich, Hafen \& Karren, 2007). Operational medical services (private) are provided to ensure quality, safety and delegate medical practices nominally according to a "direct medical direction model" (Becknell, 1997) and operate under the same conditions as public hospital governance requirements. Whilst all medical operating codes are applied, however not all private hospitals accept them equally due to cost and orientation. Thus, nursing leadership in this particularly difficult arena is seen as an important requirement to help manage emergency operational requirements (Seow, 2013) but appears to have no universal definition (Grossman \& Valiga, 2012). The nursing leadership role is also considered relatively undeveloped (Hurst, 1997) and is not openly accepted by hospital management as part of the senior nurse's managerial role (Yukl, 2013). Consequently, there is a lack of engaged conducive research in this area (IMC, 2006; Seidel, et al., 1999). There has been a call for more research in emergency departments (He, Hou, Toloo, Patrick, \& Gerald, 2011) and where this is conducted, there appears to be greater focus on the role of doctors as leaders, rather than the developing processes underpinning nursing leadership to improve the quality of patient care in emergency centres through nursing developments (Sullivan, 2012; Kohn, Corrigan \& Donaldson, 1999).

Leadership is also accepted as being important in terms of changing and improving medical performance requirements (Antrobus \& Kitson, 1999); meet the challenging and dynamic work environments within a rationalised political agenda (Gifford, Davies Edwards \& Graham, 2006; Davies, 2004); create managerial alignment and team cohesion (Callaghan, 2007); develop staff using vision, shared values and meeting expectations (Schein, 2010; Goleman, 1998); and enhance individual and group performance (James, 2009; Snow, 2001). Nursing leaders are also expected to show drive, vision and self-discipline (Pettigrew, Ferlie \& McKee, 1992; Conners, Dunn, Devine, \& Osterman, 2007) and the need to explore and learn (Anonson, et al., 2014; Antrobus \& Kitson, 1999). However, it is also recognised that emergency team effectiveness is necessary to sustain and advance patient care levels (Kohn, Corrigan \& Donaldson, 1999). Whilst the movement from the trait (Stogdill, 1948), behavioural (Bennis, 1959), and contingency (Miner, 2005) approaches have been examined, transformational leadership in health-care (Bass, 1985; Carney, 2006) appears to be a modern approach - predominantly engaged in Western countries - to help advance nursing leadership in order to build a healthy working environment (Marcus \& Liberto, 2003; Shirey, 2006; Murphy, 2005).

In Bangkok, nurses, whatever their rank, are given very strict guidelines on what skills they can perform without a doctor's direct supervision - much the same as elsewhere (O'Higgins, Ward \& Nolan, 2001). This leaves the resultant nurse's leadership role moderately limited and thus the operating medical culture restricts nursing leadership potential (Mahoney, 2001; Manley, 2000). However, associated possibilities indicate that nursing leadership appears to be dependent upon on the role the in-charge nurse wants to use as a manager - Informational, interpersonal or decisional (Sullivan, 2012). These 
orientations regulate the specific behaviours that launch leadership resolve and connect to notions such as the level of clinical expertise and the adopted business orientation - as the challenge for nursing leadership development is not just to achieve job excellence, but to enhance and maintain it (Wiggins \& Hyrkäs, 2011). However, this view disregards the role of the medical doctor in the Thai setting and lacks understanding of the doctor's power to affect team culture, contrary to Manser (2009) and materially influences the team learning capacity (Stein-Parbury \& Liaschenko, 2007) through applicable communication processes (Greenberg, et al., 2007).

\subsection{The context for EMC Operations in Private Hospitals}

The use of the mobile EMC is a very new concept that is utilised in Bangkok and in other third-world countries (Asish \& Suresh, 2016), brought about primarily from overseas patient's experiences and demands through medical interventions across borders (James, 2012). In this context, EMC staff act in the dual role of hospital staff and proto-paramedics (Neely, 1997) in difficult, chaotic circumstances, that often occurs in the EMC and therefore must also act professionally not only as a nurse in the hospital, but also as an opportunist "paramedic" (Willis \& Dalrymple, 2015). This would appear to be different to that expected in a Western hospital arena. Pre-hospital emergency incident care therefore needs to be enhanced (Liberman, Mulder, Lavoie, Denis, \& Sampalis, 2003) as there appeared to little improvement in mortality rates even when using emergency hospital transportation design specifically to get a patient from an event to hospital (Demetriade, et al., 1996).

The EMC, in private hospitals in Bangkok, are places that patients present at EMC's mostly by themselves (own cars or taxi's) and almost never directly by own hospital ambulance - except through an arranged ambulance from public hospitals. Others, from nearby accidents or incidents, are delivered only for emergency care and are only admitted into the hospital system if they can pay or have medical insurance (Farrell, 2011) - but this reflects ineffective application of appropriate consent procedures (Burges Watson, et al., 2012). Unfortunately, not all private hospitals accept emergency cases from the public (unless they are able to show clearly that they can pay prior to emergency assessment) and most have opted out from its application, as it is perceived by hospital management as too costly and cumbersome (HealthcareAsia, 2018; Bangkok Post, 2015). Consequently, a Thai patient from an emergency event is often taken to a government hospital because the emergency teams know that the patient will be admitted if necessary. Consequently, ambulance services are available for those who can demonstrate payment, otherwise the individual is taken to the nearest trauma centre (mostly by pickup truck - EMS, 2005) and then dispatched onto a government hospital ward after the patient is stabilised. Identified foreign patients are taken to the nearest hospital and are "not released" until payment is made - a sort of capture and pay method (see Bangkok Post, 2015). Further, research indicates quite clearly that private hospital emergency patients wait less time and were seen by appropriate specialist doctors; admitted earlier and had the resultant outcomes of injuries/situations earlier than when being attended to by government hospitals (Kruse, Stadhouders, Adang, Groenewoud, \& Jeurissen, 2018). Patients were there because they 
had made a financial choice for the more positive medical service provision in private hospitals (Villalonga, 2000).

The development of emergency nurse specialists as practitioners, working on par with doctors has been reported as a success in many health service institutions overseas (Clarin, 2007; Chouinard, Contandriopoulos, Perroux, \& Larouche, 2017). However, there has been little research in the role of senior nursing leaders in Emergency Medical Centres in Thailand (Tye, 1997). There have been issues raised where decisions made by a nursing "paramedic" (Atack, \& Maher, 2010). This underpins the lack of support for nursing leaders and presents a major barrier to the implementation of leadership strategies in nursing practice (Hutchinson \& Johnston, 2006; Newhouse, et al., 2012). This is viewed expressly within a doctor-centred hospital environment, as distributed (shared) leadership is not well developed, encouraged or experienced (Martin, Beech, MacIntosh, \& Bushfield, 2015) and therefore reflects a consistent lack of nursing empowerment (Wagner, et al., 2010). Strategies to overcome identified barriers to engaging nurse practitioners in emergency services remain sparse and uncoordinated (Hain \& Fleck, 2014). Having raised this issue (Arksey \& O'Malley, 2005; Househ, 2011), this creates the context for the research question, In what ways do barriers to leadership engagement and developments for Senior Nurses manifest in the operational demands of an EMC?

\section{Methodology}

Examining nursing leadership insights and developments relating to emergency practices in private hospital EMCs demands a qualitative inquiry to help discriminate more effectively the various issues (Hill, Thompson and Williams, 1997; Walsh, White \& Young, 2008). This research orientation is towards emergency medical centres (EMC) at private hospitals in Bangkok, as it is rare for private hospital ambulance to be a first-responder to an emergency incident. Consequently, the research focus targets research senior nurses' opinions as reflecting authoritive 'knowledge agent' experiences (Benn, Buckingham, Domingue \& Mancini, 2008; Sbaraini, Carter, Evans, \& Blinkhorn, 2011) through material observations and current topical practices (Sutton \& Austin, 2015). The research employed a semi-structured interview design process from a subjective knowledge perspective (Kvale, 1996) whilst exploiting an inductive/theory building approach (Glaser \& Strauss, 1967). This methodology was designed for constructing appropriate contextual data outcomes (Qu \& Dumay, 2011) underpinning richer theory development (Cayla \& Eckhardt, 2007) through shades of reflexivity (Malterud, 2001).

A pilot study was carried out with three (3) senior nursing respondents from the population and excluded from the main interview process following Maxwell (2013) that informed changes to language and the logic of possible probing questions to respondents (Kim, 2011) leading to a more rationalised questioning sequence (James \& James, 2011).

Ten (10) senior-level nursing managers (employed at Emergency Medical Centres) from single-site private hospitals were carefully targeted as a closed sample - which were all contained within an identified research frame (Ritchie \& Lewis, 2003; Fink, 2000). This research work is focused on the managerial issues raised when conducting emergency 


\section{Macrothink Institute ${ }^{\mathrm{TM}}$}

activities. Respondents were chosen by employing the approach of a closed population of interest (Carman, 1990) thus ensuring empirical adequacy (Spanos, 1990) where no senior nursing participant was considered out of research scope.

All interviews were conducted in English and took approximately one hour (Ward, et al., 2015; Sbaraini et al., 2011), which were also recorded with permission (Duranti, 2007; Orb, Eisenhauer \& Wynaden, 2001). Each individual was questioned using an identical set of prepared open questions (Gray \& Wilcox, 1995; James, 2014; Kvale, 1996), modified through the use of supplementary articulated probing questions (Balshem, 1991; Punch, 2014; Meurer, et al., 2007). Each individual verbatim transcription - applying the qualitative software package NVivo 11 (after Bailey, 2008) was returned to each respondent for comment, correction, addition or deletion and return (Harris \& Brown, 2010; Irvine, Drew \& Sainsbury, 2012; Knapik, 2006). Whole-process validity (Denzin \& Lincoln, 1998) through methodological coherence (Altheide \& Johnson, 1998) was preserved by explicitly linking the adopted main research question to the data outcomes (Stenbacka, 2001).

In terms of the data analysis procedure, each interview was initially manually examined during which discernible codes surfaced (Dey, 2005) relative to the thematic analysis (Glaser, 1992; Walsh, White \& Young, 2008; Charmaz, 2006) using NVivo 11. No narrative was left uncoded (Rubin \& Rubin, 2005; James \& James, 2011) and the complete outcome fully represented the respondent's views through cyclic-progressive coding-sequences (Buston, 1997; James, 2015; Seale \& Silverman, 1997) and were subsequently analysed to create robust rigour and illuminate the impact of their practices (Lambsdorff, 1998) in the 'public interest' (Branston, Cowling \& Sugden, 2006; Matei \& Drumasu, 2015). Themes were developed out of the data interrogation where validity was increased using triangulation processes (Onwuegbuzie \& Leech, 2007) associated with dependent media from a variety of sources (Harwood \& Garry, 2003; Ryan \& Bernard, 2003). The narrative that developed out of this quasi-mixed methodology approach (James \& James, 2011), was based on applying 'credibility' (Johnson, 1997) and 'dependability' (Lincoln \& Guba, 1985) in place of 'reliability' (Strauss \& Corbin, 1990).

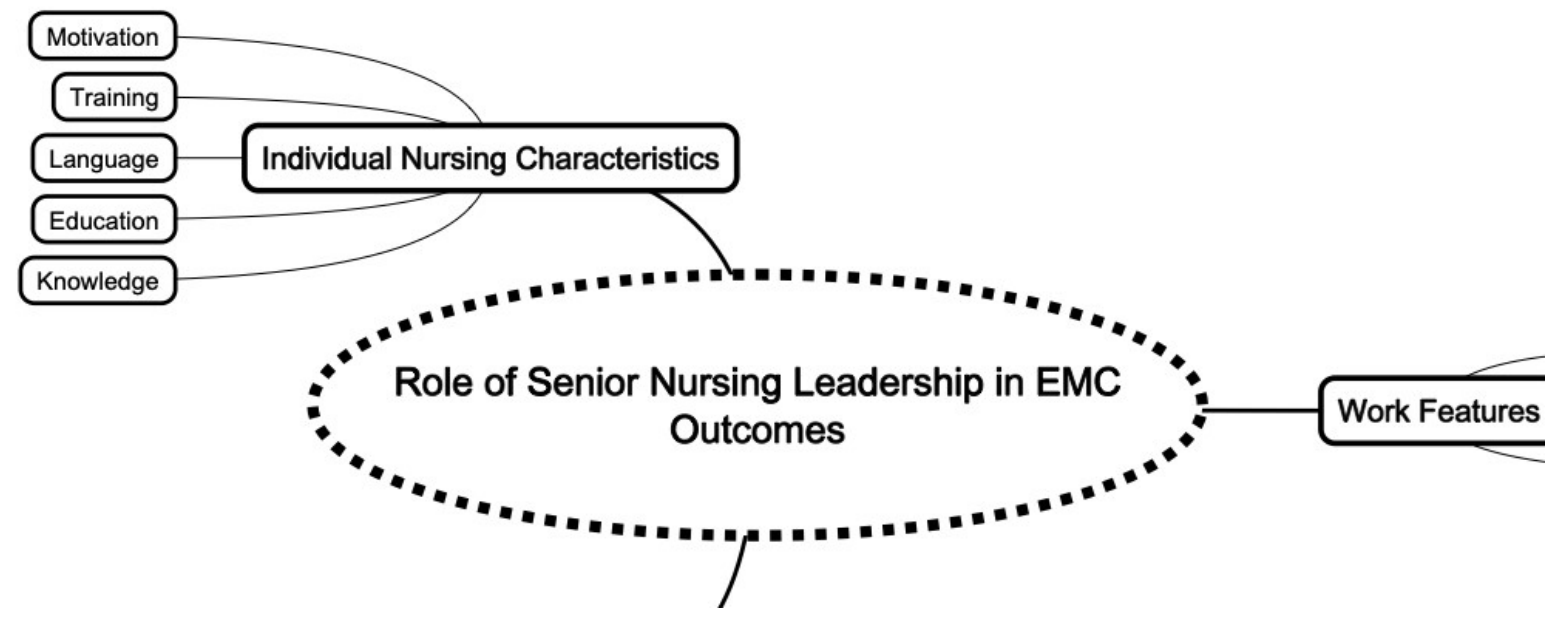

Figure 1. Research Outcomes 


\subsection{Illustration of Research Outcomes}

The research outcomes - Role of Senior Nursing Leadership in EMC - are shown in Figure 1 above is based on a layered, considered propagation (Reissmann, 2008). These outcomes are also illustrated with respondent citations and discussion targets below in Table 1 and consists of three (3) Main Themes - Individual Nursing Characteristics; System Qualities; Work Features and ten (10) sub-themes - with 248 dialogue targets. This discussion focuses on the Main-theme elements. The respondent's voice is revealed by the stated ad-verbatim dialogue, reflecting the direct expression of the respondent's opinion (Cassell \& Symon, 2004), where the reporting format is informed by Gonzalez (2008) and also Daniels, et al. (2007). Consequently, the explanations presented are considered internally coherent (Coombs, 2017) adding to the value of the consequent analysis, whilst maintaining respondent confidentiality (Kaiser, 2009).

Table 1. Research question, themes and discussion targets

\begin{tabular}{|c|c|c|c|}
\hline \multicolumn{4}{|l|}{ Research Question } \\
\hline \multicolumn{4}{|c|}{$\begin{array}{l}\text { In what ways do barriers to leadership engagement and developments for Senior Nurses manifest } \\
\text { in the operational demands of an EMC? }\end{array}$} \\
\hline Main-Themes & Sub-Themes & $\begin{array}{l}\text { Respondent } \\
\text { Citations }\end{array}$ & Discussion Targets \\
\hline \multirow{5}{*}{$\begin{array}{c}\frac{\text { Individual }}{\text { Nursing }} \\
\text { Characteristics }\end{array}$} & Motivation & 3,5 & 29 \\
\hline & Training & $1,2,8$ & 25 \\
\hline & Language & 4,10 & 22 \\
\hline & Education & 6,9 & 19 \\
\hline & Knowledge & 7,10 & 27 \\
\hline \multirow[t]{2}{*}{ System Qualities } & Regulatory & 4,6 & 16 \\
\hline & Technology & 3,8 & 26 \\
\hline \multirow[t]{3}{*}{$\underline{\text { Work Features }}$} & Teams & 5,9 & 32 \\
\hline & Mentoring and Support & 2,8 & 24 \\
\hline & Medical Direction & 1,4 & 28 \\
\hline
\end{tabular}

\section{Results}

The results are presented below, using appropriate extracted data, as centred on Gonzalez, (2008) forming useful data abstraction layers (Cassell \& Symon, 2004). Consequently, by 
considering the research question, the results are stated here as three (3) main themes, as indicated in Table 1 above, where each sub-theme theme is located and examined within each respective associated main-theme. In terms of the research consideration, the outcomes were synthesized according to the narrative adaptations (Ryan \& Bernard, 2003) and to the specific areas (Polit \& Beck, 2010) outlined in Figure 1 above - Individual Nursing Characteristics, System Elements and Work Features creating greater meaning (Bailey \& Tilley, 2002) and associated context (Bradley, Curry \& Devers, 2007). These areas of concentration indicate the particular and specific outcomes that are represented in the above senior nursing narrative and stated below:

\subsection{Main Theme - Individual Nursing Characteristics}

\section{Motivation:}

In terms of Hospital-based, this is typified by one respondent (3) suggested that, ...Here, we are all motivated to do the best we can, but it is a considerable strain doing the job, when you know they won't let you do it properly, especially if all you do is clean...

In terms of Incident-based, this is typified by one respondent (5) informed that, ...I can see that when there is an event, we are all motivated, but it is obvious that we are just standing by when we get there. Someone else takes over. I feel sorry for the patients sometimes and it upsets me...

Training:

In terms of Operational Systems this is typified by one respondent (2) suggested that, ... We do some training, but it is always hospital based. This doesn't really help in our job as it is fast changing with new technologies, new medications, new everything. But all we have is what we got 5 years ago. Nothing changes...

In terms of Planning and Logistics, this is typified by one respondent (8) advocated that, ... We are supposed to get training in management, it's in my contract. We get very little and that is nothing really, but it is always around certification renewal for the hospital. I am as qualified as it was when I started here. But because my contract is short-term I don't get any...

In terms of Response to Emergency Incidents, this is typified by one respondent (1) notified that, ... We don't do much training for incidents because we don't go to incidents at all. We wait. When we transfer a patient, because they are paying, they expect a doctor to be there, not just nurses. It is difficult to lead when you cannot take charge because it is an act of discretion on the part of the certifying doctor...

\section{Language:}

In terms of Language, this is typified by one respondent (4) reported that, ...It is right that all of our language skills are a little difficult and that most of our team members do not speak any other language other than Thai. We will have to change...

In terms of Training, this is typified by one respondent (10) advised that, ...No. We don't 
get any language training at all. It can be very dangerous with foreigners because of communications issues. It has led to failures and longer times before they get the right treatment. But we do our best...

Education:

In terms of Certifications, this is typified by one respondent (9) stated that, ...It isn't expected that we have too much education as we are nurses. Getting a degree is required for certain jobs. But most don't have the money to pay for it - But we don't get chosen?...

In terms of Financial Support, this is typified by one respondent (6) specified that, We get little support from the hospital. Why would they we are here part-time...

Knowledge:

In terms of Systems, this is typified by one respondent (7) suggested that, ...I don't feel that we have sufficient knowledge. But we do what we can. I think we need more training. People are affected by what we can do. Sometimes there are issues where we could have done better...

In terms of Technology, this is typified by one respondent (10) suggested that, ...Ohh. That can be difficult. When you are trained and tested, it seems so simple to use, but after a long time, it is difficult to remember. Especially when there are a number of casualties with different symptoms...

\subsection{Main Theme - System Qualities}

Regulatory:

In terms of Hospital-based, this is typified by one respondent (4) suggested that, ...Everyone, no matter who they are, must follow the rules. So we do. But it's not fair. We are highly trained, but we aren't allowed to show it...

In terms of Incident-based, this is typified by one respondent (6) suggested that, ...Sometimes, we treat in an emergency, but it is always checked by the doctor. They think they need to supervise everything...

Technology:

In terms of Availability, this is typified by one respondent (3) suggested that, ...Our technology is very good at base. But on the road, it is barely adequate. Our reference target to get everyone who needs to be transported because of an accident safely is very difficult to meet...

In terms of Training, this is typified by one respondent (8) suggested that, ...Sometimes it is difficult to understand what the doctor is doing. They are mostly part-time, and we have little time train together. Also, the doctor doesn't always understand the technology, but still wants to take charge...

\subsection{Main Theme - Work Features}


Teams:

In terms of Equality, this is typified by one respondent (5) indicated that, ...We work in teams, which we've been doing for a long time. But, y'know it isn't always good. Especially the way this hospital is setup. For example, I am sure about this that in teams we're equal, but not here. So, no we are there in the same uniform, representing the hospital, but we are not all in the same team...

In terms of Teamwork, this is typified by one respondent (9) suggested that, ...I can see one day we are a team - when we do drills, because no risk to anyone. But on an incident, it feels that we do what we're told. We don't all work together. Which is a shame...

Mentoring and Support:

In terms of Hospital-based, this is typified by one respondent (2) advised that, ... One thing that is not given is support after a major incident. It is like we are just left on our own, with no way of talking about our reactions. It is very difficult sometimes...

In terms of Incident-based, this is typified by one respondent (8) suggested that, ...I have never received any support from the hospital. When we get back here after an incident, it is just too chaotic anyway because we are the ones dealing with the patients...

\section{Medical Direction:}

In terms of Autocratic, this is typified by one respondent (1) reported that, ...It is good that we have doctors on our teams. But they cannot seem to take advice from nurses and just expect us to do what they say...

In terms of Inexperienced, this is typified by one respondent (4) suggested that, ...He's a good doctor really. But he is not experienced in emergency matters - he's learning. However, you must do what he says straight away or else he creates problems for you. He's not the only one. We just stand and listen, take blood pressure, clean woods, bandage etc. Not what you would expect from highly trained nurses who want to lead...

\section{Discussion - Research Consideration and Implications}

The results are discussed below as a discursive analysis using a persistent taxonomy approach (Westhues et al., 2008) that emerges from reframing the narrative (Popay, et al., 2006; Jantzen, 2008; Snilstveit, Oliver \& Vojtkova, 2012) through robust induction (Morse, 2018) and elucidated as:

\subsection{Individual Nursing Characteristics}

It would appear that from the data statements that the EMC arena is predicated with formal leadership resulting from expertise (resulting from training, education and experience) and job position (application of knowledge) (Sullivan \& Decker, 2005), where the decision-making role of the doctor is considered paramount (First, Tomlins \& Swinburn, 2012). Informal leadership practices would appear to be prevalent in the nursing healthcare culture (Downey, Parslow \& Smart, 2011; Ross, 2014), but are considered secondary to the need to follow the command culture through applicable procedures, 
policies and systems (Lawson, Tecson, Shaver, Barnes, \& Kavli, 2018). As the EMC arena is controlled by doctors through formal/position leadership, nursing leaders appeared to perceive that they had a lack of opportunity to view important clinical details/evidence ((Melnyk, et al, 2012) revolving around the doctors grasp of protecting clinical scope and practices leading to ineffective collaboration opportunities (Clarin, 2007). The data further suggests that this appears to have led to low motivation levels among senior nursing staff through lack of further opportunities to engage with peers and colleagues (De Milt, Fitzpatrick \& McNulty, 2011; Morey, et al., 2002). However, this could provide opportunities to deliver role expansion for nurses through collaborative competence, which is rational and in-line with the development of low-hierarchal mechanisms within emergency service teams (Golden \& Miller, 2013). Engaging in appropriate patterns of communications (Pentland, 2012) may also help nursing leaders can become more effective (Stanley, 2006a) especially through necessary and wider linguistic developments. This is seen as an important issue, as communication between the emergency personnel and the patient revolves around, in part, to the material understanding of protection and securing the safety of the patient as well the emergency team and underpinned by the consent protocols.

Senior nurses appear to be motivated to enhance their skillsets (Bishop \& Scott, 2001) and would welcome the opportunity to extend their professional role through certifications (Jansen, 2006) leading to specialised nursing capabilities (Cox \& Hill, 2010). However, funding and material professional bias, may prevent such nurses moving beyond just an ancillary role in EMC practices. This further indicates a current and imperative impediment to enhancing nursing professional identity (Hallam, 2000).

\subsection{System Qualities}

A major requirement for senior nurses as practitioners in an emergency situation requires a regulatory authority to prescribe appropriate medication for relevant to the diagnosis of injuries or disease found (Avery \& Pringle, 2005; Regulatory Agency Consultation, 2006) - this is an aspect that in Thailand cannot be done without formal medical direction - that is by a registered doctor. Consequently, senior nurses perceived an over-reliance on doctors' input into explicit emergency care, where the nurses consolidated experience and understanding could be effectively used to enhance the care a patient receives (Elcigil, et al., 2011). This however, continues to be perceived as a significant barrier affecting senior nursing practitioner's leadership progress and the outcome of which must be more positively assessed by the regulatory authority in Thailand - especially considering that in many other parts of the world this is essentially a very optimistic future move underpinning improved patient safety (Blanchflower, Greene \& Thorp, 2013; Jones, Edwards \& While, 2010; Latter \& Courtenay, 2004).

Senior nurses appear to conclude that there are certain medical technologies they can use, and others they cannot use and are therefore persuaded that certain certifications are beyond their reach such as "prescribing rights" (Courtenay, Carey \& Burke, 2007; Hall, 2004) - thus limiting their scope of "expert" practices (Adams, Miller, \& Beck, 1996). This does little to address the needs of the emergency situation or the consistent 
development and provision of suitable clinical experts (Black, 2014; Field, 2004).

The data indicated that regulatory mechanisms/determinations prevented nurse leaders from acting as emergency team heads (Hain \& Fleck, 2014). Moving senior nurses forward towards being certified to world-level acknowledged EMS requirements, may provide the confidence and approach to balance and satisfy patient safety performance (Lievens \& Vlerick, 2014). Further, broadening the operational scope of senior nurses who can demonstrate appropriate professional capability and experience in managing and leading EMC practices (Cathcart \& Fillipon, 2012) - should help senior nurses' practice and reinforce their capabilities (Fairman, et al., 2011) through elevated interprofessionality engagement (D'Amour \& Oandasan, 2005).

\subsection{Work Features}

The data indicated clearly that the emergency teams did not act as teams, which reflected vital information being lost because of the adverse group dynamics perceptions (Sakran, et al., 2012) - resulting out of lack of power and opportunity to lead (Wilson \& Laschinger, 1994), thus restricting senior nurses leadership options. This illustrates the ineffectiveness of a hierarchy and the need for integrated teams (Manser, 2009) when confronted with a dangerous, dynamic work environment where expert knowledge and skills are more important to raise the effectiveness of overall nursing team leadership (Stanley, 2006b).

The engaged narrative suggests clearly that senior nurses do not have the authority to carry out independent actions, despite their perceptions of what constitutes good nursing care (Cody \& Squire, 1998). Consequently, nurses did not act outside their limited remit unless they had explicit legitimate authority to do so, which was never given. This appeared to represent significant underlying nurses' issues in explicit "doctor-centred" emergency managed situations (Choctaw, 2016), reinforced through training practices and policies (Cathcart \& Fillipon, 2012). In this respect, lack of opportunities to engage in effective leadership practices (Cummings, Lee \& McGregor, et al., 2008) is seen as a barrier to underpinning their professional status. Further, the present level of nursing leadership is characterised as reflecting a dependent actions approach demanding less-appropriate professional experience and qualifications as nominal emergency care practitioners (Halter, Marlow, Tye, \& Ellison, 2006) which is experienced within a forced systematic "intentional leadership culture" development created to obviate nursing leaders (Joseph \& Huber, 2015; Hyde, 2010). This, however, can be influenced more positively by managing the medical situation and practice through distinctive role distribution and information flow (Pearce \& Sims, 2002).

The possibility of moving towards an evidence-based decision-making process for emergency practices and care may help to support nursing clinical decisions and outcomes and enhance the possibilities for gaining appropriate levels of leadership (Melnyk, et al, 2012) through collaboration (Ford, et al., 2016). This will also have the effect of enhancing the delivery of care and motivate nurses to seek leadership opportunities (Tomey, 2009) as well as providing a useful platform for applying transformational leadership perspectives for senior nurses (McGuire \& Kennerly, 2006). 
The data further indicates that doctors opposed the increased professionalising of nurses, which suggested that doctors perceived that developing nursing practices were an attack on the scope of doctors professional undertaking (Fairman, Rowe, Hassmiller, \& Shalala, 2011) or result from fear of litigation (O’Brien, Martin, Heyworth, \& Meyer, 2008). Consequently, the lack of non-pharmacologic modalities ascribed to senior nurses decision-making competencies (Johnson, Kassner, Houser, \& Kutner, 2005) raises concerns. Clearly, the professional emergency medical culture in Bangkok has not progressed as in other countries because of contingent/shared leadership (Yun, Faraj \& Sims, 2005) that requires energy and direction to professionally integrate more effectively (Miller, et al., 2008; Ajeigbe, McNeese-Smith, Phillips, \& Leach, 2014). This indicates a predominance of nurses as followers, rather than as leaders, amid a closed-cultural resistance to change (Laura, 2012; Hatch, 1993) thus reducing senior nurses' future capability to become exemplary leaders (Hain \& Fleck, 2014) and restrict their ability to "take-charge" in emergency situations.

Lack of compliance with limited standardised clinical guidelines was offered as a major barrier across the spectrum of emergency personnel (Williams, Campbell, Henry, \& Collier, 1994), as the doctor's approach changed according to their experience - and was also influenced by the hospital that they were seconded from - as most doctors work part-time in the private arena.

\section{Conclusions}

Senior nurses should be seen as a vital experienced resource for the effective management of EMC activities both inside and outside of the hospital. Nursing leadership developments reflecting nursing professionals seeking more responsibility (Devi, 2011) in Bangkok appear misaligned, non-progressive, lacking effective inter-professional acceptance and practices through job scope curtailment (Magid, et al., 2009) and the empowerment necessary for consistent nursing development (Laschinger, 1996; DeVivo, Quinn Griffin, Donahue, \& Fitzpatrick, 2011). Further, nursing developments that underpin processes to create and provide a coherent team-based culture is compulsory to enhance the safety of patients (Kohn, Corrigan \& Donaldson, 1999), improve performance (Morey, et al., 2002) which must be supported by the hospital management (Korley, Morton \& Hill, 2013).

Whole-team involvement at the professional level in difficult emergency situations requires the nursing leadership role to be recognised and utilised in order to ensure the heightened duty of care for emergency incident patients by enhancing communications (Clements, Curtis, Horvat, \& Shaban, 2015), solidifying whole-team collaboration and support (Greenfield, 2007; Carter, et al., 2010) and to utilise the significant leadership potential of nurses (Davidson, Elliot \& Daly, 2006). Nevertheless, the research outcomes suggest a logical and coherent need for structurally significant changes to the regulatory/management culture (Ford, et al., 2016) that presently supports doctors and other senior administrators as the only individuals who can medically direct at an emergency scene. Existing hospital and regulation guidance on nursing leadership within a doctor-directed culture restricts the positive effects of shared experiences (Francis, 2013; 
Lovegrove \& Davis, 2013). Further, senior nurses' inability to administer opioids (Elcigil, Maltepe, Esrefgil, \& Mutafoglu, 2011) and execute emergency job requirements without supervision reduces job scope (Edmonson, Sumagaysay, Cueman, \& Chappell, 2016), impacts on job satisfaction (Casida \& Pinto-Zipp, 2008), affects professional relationships (Bianco, Dudkiewicz \& Linette, 2014) and hinders productive team communications (Chadwick, 2010). One measure may be to move the EMC towards an innovation culture (Omachonu \& Einspruch, 2010), thus reducing vertical barriers and introducing leadership based on knowledge, capability, efficiency and motivation, rather than be positioned by stagnated mechanistic measures aligned to doctor requirements associated with top-down management (James, 2005), rather than horizontal leadership patterns. Consequently, there appear to be many barriers to nursing development and acceptance for those nurses aspiring to become nurse leaders in Bangkok. These barriers need to reduced to help ensure the overall development of EMC teams and improve senior nursing leadership practices and opportunities.

\section{References}

Adams, D., Miller, B., \& Beck, I. (1996). Professionalism behaviors of hospital nurse executives and middle managers in 10 western states. West Journal of Nursing Research, 18(1), 77-88. https://doi.org/10.1177/019394599601800106

Ajeigbe, D., McNeese-Smith, D., Phillips, L., \& Leach, L. (2014). Effect of Nurse-Physician Teamwork in the Emergency Department Nurse and Physician Perception of Job Satisfaction. Journal of Nursing \& Care, 3(1), 141-148. https://doi.org/10.4172/2167-1168.1000141

Altheide, D., \& Johnson, J. (1998). Criteria for assessing interpretive validity in qualitative research, (283-312). In N. Denzin, \& Y. Lincoln, (Eds.), Collecting and interpreting qualitative materials. Thousand Oaks, CA, USA: Sage Publications.

Anonson, J., Walker, M., Arries, E., Maposa, S., Telford, P., \& Berry, L. (2014). Qualities of exemplary nurse leaders: perspectives of frontline nurses. Journal of Nursing Management, 22(1), 127-136. https://doi.org/10.1111/jonm.12092

Antrobus, S., \& Kitson, A. (1999). Nursing leadership - Influencing and shaping health policy and nursing practice. Journal of Advanced Nursing, 29(3), 746-753. https://doi.org/10.1046/j.1365-2648.1999.00945.x

Arksey, H., \& O'Malley, L. (2005). Scoping studies: Towards a Methodological Framework. International Journal of Social Research Methodology, 8(1), 19-32. https://doi.org/10.1080/1364557032000119616

Asish, K., \& Suresh, V. (2016). Setting up and functioning of an Emergency Medicine Department: Lessons learned from a preliminary study. Indian Journal of Anaesthesia, 60(2), 108-114. https://doi.org/10.4103/0019-5049.176273

Atack, L., \& Maher, J. (2010). Emergency medical and health providers' perceptions of key issues in prehospital patient safety. Prehospital Emergency Care, 14(1), 95-102. 
https://doi.org/10.3109/10903120903349887

Avery, A., \& Pringle, M. (2005). Extended prescribing by UK nurses and pharmacists. British Medical Journal, 331(7526), 1154-1155. https://doi.org/10.1136/bmj.331.7526.1154

Bailey, K. (2008). Methods of Social Research. New York, USA: The Free Press.

Bailey, P., \& Tilley, S. (2002). Storytelling and the interpretation of meaning in qualitative research. Journal of Advanced Nursing, 38(6), 574-583. https://dx.doi.org/10.1046/j.1365-2648.2000.02224 .x

Balshem, M. (1991). Cancer, Control and Causality: Talking about Cancer in a Working-Class Community. American Ethnologist, 18(1), 152-172. https://doi.org/10.1525/ae.1991.18.1.02a00070

Bangkok Post. (2015). Emergency treatment: Private hospitals refuse govt regulation. Retrieved from https://www.bangkokpost.com/learning/learning-news/556787/emergency-treatment-privat e-hospitals-refuse-govt-regulation

Bass, B. (1985). Leadership and performance beyond expectations. New York, USA: The Free Press.

Becknell, J. (1997). The benevolent dictator. A new breed of medical director. Journal of Emergency Medical Services, 22(7), 36-40. PMID: 10168767

Benn, N., Buckingham, S., Domingue, J., \& Mancini, C. (2008). Ontological Foundations for Scholarly Debate Mapping Technology. In 2nd International Conference on Computational Models of Argument (COMMA '08), Toulouse, France.

Bennis, W. (1959). Leadership Theory and Administrative Behaviour: The Problem of Authority. Administrative Science Quarterly, 4(2), 259-301.

Bianco, C., Dudkiewicz, P., \& Linette, D. (2014). Nursing Management, 45(5), 42-48. https://doi.org/10.1097/01.NUMA.0000442635.84291.30

Bishop, V., \& Scott, I. (2001). Challenges in Clinical Practice. Hampshire, UK: Palgrave.

Black, B. (2014). Professional Nursing: concepts \& challenges. St Louis, USA: Saunders, an Imprint of Elsevier.

Blanchflower, J., Greene, L., \& Thorp, C. (2013). Breaking through barriers to nurse prescribing. Nursing Times, 109(31/32), 12-13. Retrieved from www.nursingtimes.net

Bradley, E., Curry, L., \& Devers, K. (2007). Qualitative data analysis for health services research: Developing taxonomy, themes, and theory. Health Services Research, 42(4), 1758-1772. https://doi.org/10.1111/j.1475-6773.2006.00684.x

Branston, J., Cowling, K., \& Sugden, R. (2006). Corporate Governance and the Public Interest. International Review of Applied Economics, 20(2), 189-212. 
https://doi.org/10.1080/02692170600581110

Burges Watson, D., Sanoff, R., Mackintosh, J., Saver J., Ford, G., Price, C., ...Murtagh J. (2012). Evidence From the Scene: Paramedic Perspectives on Involvement in Out-of-Hospital Research. Annals of Emergency Medicine, 60(5), 641-650. https://doi.org/10.1016/j.annemergmed.2011.12.002

Buston, K. (1997). NUD*IST in action: its use and its usefulness in a study of chronic illness in young people. Sociological Research Online, 2(3), 1-13. https://doi.org/10.5153/sro.89

Callaghan, L. (2007). Advanced nursing practice: An idea whose time has come. Journal of Clinical Nursing, 17(2), 205-213. https://doi.org/10.1111/j.1365-2702.2006.01881.x

Carman, J. (1990). Consumer Perceptions of Service Quality: An Assessment of the SERVQUAL Dimensions. Journal of Retailing, 66(1), 33-55.

Carney, M. (2006). Health Service Management: Consensus, Culture and the Middle Manager. Cork, Ireland: OakTree Press.

Carter, N., Martin-Misener, R., Kilpatrick, K., Kaasalainen, S., Donald, F., Bryant-Lukosius, D., ...DiCenso, A. (2010). The Role of Nursing Leadership in Integrating Clinical Nurse Specialists and Nurse Practitioners in Healthcare Delivery in Canada. Advanced Nursing Practice, 23, December, 167-185. PMID: 21478692

Casida, J., \& Pinto-Zipp, G. (2008). Leadership-Organizational Culture Relationship in Nursing Units of Acute Care Hospitals. Nursing Economic, 26(1), 7-15.

Cassell, C., \& Symon, G. (2004). Essential Guide to Qualitative Methods in Organizational Research. London, UK: Sage Publications.

Cathcart, E., \& Fillipon, K. (2012). Strengthening the Practice of Nursing, 39-46. In M. Hickey, \& P. Kritek, (2012). (Eds.), Change Leadership in Nursing. (Eds). New York, USA: Springer Publishing.

Cayla, J., \& Eckhardt, G. (2007). Asian Brands without Borders: Regional Opportunities and Challenges. International Marketing Review, 24(4), 444-456. https://doi.org/10.1108/02651330710761017

Chadwick, M. (2010). Creating order out of chaos: A leadership approach. Association of Operating Room Nurses. AORN Journal, 91(1), 154-170. https://doi.org/10.1016/j.aorn.2009.06.029

Charmaz, K. (2006). Constructing Grounded Theory: A Practical Guide through Qualitative Analysis. London, UK: Sage Publications.

Chouinard, V., Contandriopoulos, D., Perroux, M., \& Larouche, C. (2017). Supporting nurse practitioners' practice in primary healthcare settings: a three-level qualitative model. BMC Health Services Research, 17(1), 437. https://doi.org/10.1186/s12913-017-2363-4

Clarin, O. (2007). Strategies to overcome barriers to effective nurse practitioner and 
physician collaboration. The Journal for Nurse Practitioners, 3(8), 538-548. https://doi.org/10.1016/j.nurpra.2007.05.019

Clements, A., Curtis, K., Horvat, L., \& Shaban, R. (2015). The effect of a nurse team leader on communication and leadership in major trauma resuscitations. International Emergency Nursing, 23(1), 3-7. https://doi.org/10.1016/j.ienj.2014.04.004

Cody, A., \& Squire, A., (1998). Nurse's perceptions of good nursing care. Professional Nurse, 13(9), 578-582. PMID:9782973

Choctaw, W. (2016). Transforming the Patient Experience. New York, USA: Springer International Publishing.

Conners, S., Dunn, R., Devine, K., \& Osterman, C. (2007). Strategies for cultivating nursing leadership. Nurse Leader, 5(5), 26-32. https://doi.org/10.1016/j.mnl.2007.07.005

Coombes, C. (2017). Coherence and transparency: some advice for qualitative researchers. Production, 27. https://doi.org/10.1590/0103-6513.006817

Courtenay, M., Carey, N., \& Burke, J. (2007). Independent extended supplementary nurse prescribers, their prescribing practice and confidence to educate and assess prescribing $\begin{array}{llll}\text { students. Nurse } & \text { Education } & \text { 739-747. }\end{array}$ https://doi.org/10.1016/j.nedt.2006.10.007

Cox, C., \& Hill, M. (2010). Professional Issues in Primary Care Nursing. (Eds). Chichester, UK: Wiley-Blackwell.

Cummings, G., Lee, H., McGregor, T., Davey, M., Wong, C., Paul, L., \& Stafford, E. (2008). Factors contributing to nursing leadership: a systematic review. Journal of Health Services Research and Policy, 13(4), 240-248. https://doi.org/10.1258/jhsrp.2008.007154

D'Amour, D., \& Oandasan, I. (2005). Interprofessionality as the field of interprofessional practice and interprofessional education: An emerging concept. Journal Interprofessional Care, 19(Sup 1), 8-20. https://doi.org/10.1080/13561820500081604

Daniels, J., Bradley, M., Cramer, D., Winkler, A., Kinebrew, K., \& Crockett, D. (2007). The Successful Resolution of Armed Hostage/Barricade Events in Schools: A Qualitative Analysis. Psychology in the Schools, 44(6), 601-613. https://doi.org/10.1002/pits.20250

Davidson, P., Elliot, D., \& Daly, J. (2006). Clinical leadership in contemporary clinical practice: implications for nursing in Australia. Journal of Nursing Management, 14(3), 180-187. https://doi.org/10.1111/j.1365-2934.2006.00555.x

Davies, C. (2004). Political leadership and the politics of nursing. Journal of Nursing Management, 12(4), 235-41. https://doi.org/10.1111/j.1365-2834.2004.00477.x

De Milt, D., Fitzpatrick, J., \& McNulty, S. (2011). Nurse practitioners' job satisfaction and intent to leave current positions, the nursing profession, and the nurse practitioner role as a direct care provider. Journal of the American Academy of Nurse Practitioners, 23(1), 42-50. https://doi.org/10.111/j.1745-7599.2010.00570.x 
Demetriades, D., Chan, L., Cornwell, E., Belzberg, H., Berne, T., Asensio, J., ...Alo K. (1996). Paramedic vs private transportation of trauma patients. Effect on outcome. Arch Surg, 131(2), 133-138. https://doi.org/10.1001/archsurg.1996.01430140023007

Denzin, N., \& Lincoln, Y. (1998). Strategies of Qualitative Inquiry. London, UK: Sage Publications.

Devi, S. (2011). US nurse practitioners push for more responsibilities. The Lancet, 377(9766), 625-626. https://doi.org/10.1016/S0140-6736(11)60214-6

DeVivo, D., Quinn Griffin, M., Donahue, M., \& Fitzpatrick, J. (2011). Perceptions of Empowerment Among ED Nurses. Journal of Emergency Nursing, 39(6), 529-533. https://doi.org/10.1016/j.jen.2010.10.011

Dey, I. (2005). Qualitative data analysis. London, UK: Routledge.

Downey, M., Parslow, S., \& Smart, M. (2011). The hidden treasure in nursing leadership: informal leaders. Journal of Nursing Management, 19(4), 517-521. https://doi.org/10.1111/j.1365-2834.2011.01253.x

Duranti, A. (2007). Transcripts, like Shadows on a Wall. Mind, Culture, and Activity, 13(4), 301-310. https://doi.org/10.1207/s15327884mca1304_3

Edmonson, C., Sumagaysay, D., Cueman, M., \& Chappell, S. (2016). Crisis Management: The Nurse Leader's Role. Nurse Leader, June, 174-176. https://dx.doi.org/10.1016/j.mnl.2016.04.003

Elcigil, A., Maltepe, H., Esrefgil, G., \& Mutafoglu, K. (2011). Nurses' Perceived Barriers to Assessment and Management of Pain in a University Hospital. Journal of Pediatric Hematology/Oncology, 33, S33-38. https://doi.org/10.1097/mph.0b013e3182121bef

EMS. (2005). Current Status of EMS in Thailand. Thai Swedish EMS Collaboration. Retrieved from https://www.niems.go.th

Fairman, J., Rowe, J., Hassmiller, S., \& Shalala, D. (2011). Broadening the scope of nursing practice. New England Journal of Medicine, 364(3), 193-196. https://doi.org/10.1056/NEJMp1012121

Farrell, J. (2011). The Thai Health Care System. Chiangmaicitylife.com. Retrieved from http://www.chiangmaicitylife.com/citylife-articles/the-thai-health-care-system/

Field, D. (2004). Moving from novice to expert - The value of learning in clinical practice: A literature review. Nurse Education Today, 24(7), 560-565. https://doi.org/10.1016/j.nedt.2004.07.009

Fink, A. (2000). The Role of the Researcher in the Qualitative Research Process. A Potential Barrier to Archiving Qualitative Data. Forum: Qualitative Social Research, 1(3), article 4. Retrieved from http://nbn-resolving.de/urn:nbn:de:0114-fqs000344

First, S., Tomlins, L., \& Swinburn, A. (2012). From trade to profession-the professionalisation of the paramedic workforce. Journal of Paramedic Practice, 4(7), 
378-381. https://doi.org/10.12968/jpar.2012.4.7.378

Ford, K. Menchine, M., Burner, E., Arora, S., Inaba, K., Demetriades, D., \& Yersin, B. (2016). Leadership and Teamwork in Trauma and Resuscitation. West Journal of Emergency Medicine, 17(5), 549-556. https://doi.org/10.5811/westjem.2016.7.29812

Francis, R. (2013). Lessons learnt and related key recommendations. Report of the Mid Staffordshire NHS Foundation Trust Public Enquiry. Executive Summary. (65-84). London, UK: The Stationery Office.

Gifford, W., Davies B., Edwards N., \& Graham, I. (2006). Leadership strategies to influence the use of clinical practice guidelines. Canadian Journal of Nursing Leadership, 19(4), 72-87. https://doi.org/10.12927/cjnl.2006.18603

Glaser, B. (1992). Basics of Grounded Theory Analysis. Mill Valley, CA, USA: Sociology Press.

Glaser, B., \& Strauss, A. (1967). The Discovery of Grounded Theory: Strategies for Qualitative Research. Chicago, USA: Aldine.

Golden, A., \& Miller, K. (2013). Championing truly collaborative team-based care. Annals of Internal Medicine, 159(9), 642-643. https://doi.org/10.7326/0003-4819-1589-9-201311050-00714

Goleman, D. (1998). What makes a leader? Harvard Business Review, 76(6), 93-102. www.HBR.org

Gonzalez, C. (2008). Conceptions of, and approaches to, teaching online: a study of lecturers teaching postgraduate distance courses. Higher Education, 57(3), 299-314. https://doi.org/10.1007/s10734-008-9145-1

Gray, J., \& Wilcox, B. (1995). Good Schools, Bad Schools. Milton Keynes, UK: Open University Press.

Greenberg, C., Regenbogen, S., Studdert, D., Lipsitz, S., Rogers, S., Zinner, M., \& Gawande, A. (2007). Patterns of communication breakdowns resulting in injury to surgical patients. Journal Am. Coll. Surg, 204(4), 533-540. https://doi.org/10.1016/j.jamcollsurg.2007.01.010

Greenfield, D. (2007). The enactment of dynamic leadership. Leadership in Health Services, 20(3), 159-168. https://doi.org/10.1108/17511870710764014

Grossman, S., \& Valiga, T. (2012). The new leadership challenge - Creating the future of nursing, $4^{\text {th }}$ ed. Philadelphia, USA: FA Davis Company.

Hain, D., \& Fleck, L. (2014). Barriers to NP Practice that Impact Healthcare Redesign. American Nursing Association, 19(2), man.2. https://doi.org/10.3912/OJIN.Vol19No02Man02

Hall, J. (2004). Can we learn from nurse prescribing? The Pharmaceutical Journal, 272(7282), 56. 
Hallam, J. (2000). Nursing the Image. London, UK: Routledge.

Halter, M., Marlow, T., Tye, C., \& Ellison, G. (2006). Patients' experiences of care provided by emergency care practitioners and traditional ambulance practitioners: A survey from the London ambulance service. Emergency Medicine Journal, 23, 865-866. https://doi.org/10.1136/emj.2005.032912

Harris, L., \& Brown, G. (2010). Mixing interview and questionnaire methods: Practical problems in aligning data. Practical Assessment, Research and Evaluation, 15(1), 1-19.

Harwood, T., \& Garry, T. (2003). An Overview of Content Analysis. The Marketing Review, 3(4), 479-498. https://doi.org/10.1362/146934703771910080

Hatch, M. (1993). The dynamics of organizational culture. Academy of Management Review, 18(4), 657-693. https://doi.org/10.5465/amr.1993.9402210154

He, J., Hou, X., Toloo, S., Patrick, J., \& Gerald, G. (2011). Demand for hospital emergency departments: a conceptual understanding. World Journal of Emergency Medicine, 2(4), 253-261. https://doi.org/10.5847/wjem.j.1920-8642.2011.04.002

HealthcareAsia. (2018). Why Thailand is pressed to revamp healthcare. $26^{\text {th }}$ January. Retrieved from https://healthcareasiamagazine.com/healthcare/news/why-thailand-pressed-revamp-healthc are

Hill, C., Thompson, B., \& Williams, E. (1997). A guide to conducting consensual qualitative research. The Counseling Psychologist, 25(4), 517-572. https://doi.org/10.1177/0011000097254001

Househ, M. (2011). Sharing sensitive personal health information through Facebook: the unintended consequences. Studies in Health Technology and Informatics, 169, 616-620. https://doi.org/10.3233/978-1-60750-806-9-616

Hurst K. (1997). A Review of the Nursing Leadership Literature. Leeds, UK: Nuffield Institute, University of Leeds.

Hutchinson, A., \& Johnston, L. (2006). Beyond the barriers scale: Commonly reported barriers to research use. The Journal of Nursing Administration, 36(4), 189-199. PMID: 16609341

Hyde, P. (2010). Changing relationships between health service managers: Confrontation, collusion and collaboration. In J., Braithwaite, P., Hyde, \& C. Pope (Eds.), Culture and climate in health care organizations. Basingstoke, England, UK: Palgrave MacMillan.

IMC. (2006). Institute of Medicine Committee on the Future of Emergency Care in the United States Health System. Emergency Medical Systems (EMS): At the Crossroads. Washington DC, USA: The National Academies Press.

Irvine, A., Drew, P., \& Sainsbury, R. (2012). "Am I not answering your questions properly?" Clarification, adequacy and responsiveness in semi-structured telephone and 
face-to-face interviews. 2020, Vol. 12, No. 3

https://doi.org/10.1177/1468794112439086

James, P. (2015). Social Media Marketing Developments in Private Hospitals in Bangkok. The Internet Journal of Healthcare Administration, 11(1). https://doi.org/10.5580/IJHCA.35596

James, P. (2014). Managerial Challenges Impacting on Contractor Led Tunnel TBM Design: A Kingdom of Saudi Arabia Metro Project. Engineering Management Research, 3(2), November, 2014. https://doi.org/10.5539/emr.v3n2p32

James, P. (2012). The impact of medical tourism on Thai private hospital management: informing hospital policy. Global Journal of Health Science, 4(1), 127-139.

James, P., \& James, T. (2011). Qualitative Research Methods for Health Services. London, UK: Megellan UK Press.

James, P. (2009). The Management Functions of TQM. Southampton, UK: Quality Business Books.

James, P. (2005). Total Quality Management in Asia: Practices for the 21st Century. Singapore Pearson.

Jansen, M. (2006). Professional Issues: Licensure, Certification, Prescriptive Privileges, Credentialing, and Legal Issues, 107-120. In M., Jansen, \& M. Zwygart-Stauffacher, (Eds), Advanced Practice Nursing. New York, USA: Springer Publishing Company.

Jantzen, D. (2008). Reframing professional development for first-line nurses. Nursing Inquiry, 15(1), 21-29. https://doi.org/10.1111/j.1440-1800.2008.00394.x

Johnson, B. (1997). Examining the validity structure of qualitative research. Education, $118(3), 282-292$.

Johnson, D., Kassner, C., Houser, J., \& Kutner, J. (2005). Barriers to effective symptom management in hospice. Journal of Pain Symptom Management, 29(1), 69-79. https://doi.org/10.1016/j.jpainsymman.2004.09.001

Jones, K., Edwards, M., \& While, A. (2010). Nurse prescribing roles in acute care: an evaluative case study. Journal of Advanced Nursing, 67(1), 117-126. https://doi.org/10.1111/j.1365-2648.2010.05490.x

Joseph, L., \& Huber, D. (2015). Clinical leadership development and education for nurses: prospects and opportunities. Journal of Healthcare Leadership, 7, 55-64. https://dx.doi.org/10.2147\%2FJHL.S68071

Kaiser, K. (2009). Protecting Respondent Confidentiality in Qualitative Research. Qualitative Health Research, 19(11), 1632-1641. https://doi.org/10.1177/1049732309350879

Kim, Y. (2011). The Pilot Study in Qualitative Inquiry: Identifying Issues and Learning Lessons for Culturally Competent Research. Qualitative Social Work, 10(2), 190-206. 
https://doi.org/10.1177/1473325010362001

Knapik, M. (2006). The Qualitative Research Interview: Participants' Responsive Participation in Knowledge Making. International Journal of Qualitative Methods, 5(3), 77-93. https://doi.org/10.1177/160940690600500308

Kohn, L., Corrigan, J., \& Donaldson, M. (1999). To Err is Human: Building a Safer Health System. Washington, DC, USA: National Academy Press.

Korley, F., Morton, M., Hill, P., Mundangepfupfu, T., Zhou, T., Mohareb, A., \& Rothma, R. (2013). Agreement between routine emergency department care and clinical decision support recommended care in patients evaluated for mild traumatic brain injury. Academic Emergency Medicine, 20(5), 463-469. https://doi.org/10.1111/acem.12136

Kruse, F., Stadhouders, N., Adang, E., Groenewoud, S., \& Jeurissen, P. (2018). Do private hospitals outperform public hospitals regarding efficiency, accessibility, and quality of care in the European Union? A literature review. The International Journal of Health Planning and Management, 33(2), 1-20, e434-e453. https://doi.org/10.1002/hpm.2502

Kvale, S. (1996). Interviews: An Introduction to Qualitative Research Interviewing. Thousand Oaks, CA, USA: Sage Publications.

Lambsdorff, G. (1998). An Empirical Investigation of Bribery in International Trade. European Journal for Development Research, 10(1), 40-59. https://doi.org/10.1080/09578819808426701

Laschinger, H. (1996). A theoretical approach to studying work empowerment in nursing: a review of studies testing Kanter's theory of structural power in organizations. Nursing Administration Quarterly, 20(2), 25-41. https://doi.org/10.1097/00006216199602020-00006

Latter, S., \& Courtenay, M. (2004). Effectiveness of nurse prescribing: a review of the $\begin{array}{lllll}\text { literature. Issues in } \quad \text { Clinical } & \text { Nursing, }\end{array}$ https://doi.org/10.1046/j.1365-2702.2003.00839.x

Laura, W. (2012). Barriers to Implementing Evidence-Based Practice Remain High for U.S. Nurses. American Journal of Nursing, 112(12), 15. https://doi.org/10.1097/01.NAJ.0000423491.98489.70

Lawson, D., Tecson, K., Shaver, C., Barnes, S., \& Kavli, S. (2018). The impact of informal leader nurses on patient satisfaction. Journal of Nursing Management, https://doi.org/10.1111/jonm.12653

Liberman, M., Mulder, D. Lavoie, A. Denis, R., \& Sampalis, J. (2003). Multicenter Canadian Study of Prehospital Trauma Care. Annals of Surgery, 237(2), 153-160.

Lievens, I., \& Vlerick, P. (2014). Transformational leadership and safety performance among nurses: the mediating role of knowledge-related job characteristics. Journal of Advanced Nursing, 70(3), 651-661. http://doi.org/10.1111/jan.12229 
Lincoln, Y., \& Guba, E. (1985). Naturalistic Inquiry. Beverly Hills, CA., USA: Sage Publications.

Lovegrove, M., \& Davis, J. (2013). Maximising paramedics' contribution to the delivery of high quality and cost effective patient care. High Wycombe, England, UK: Buckinghamshire New University.

Magid, D., Sullivan, A., Cleary P., Rao, S., Gordon, J., Kaushal, R., ...Blumenthal, D. (2009). The safety of emergency care systems: results of a survey of clinicians in 65 US emergency departments. Annals Emergency Medicine, 53(6), 715-723. https://doi.org/10.1016/j.annemergmed.2008.10.007

Mahoney, J. (2001). Leadership skills for the 21st century. Journal of Nursing Management, 9(5), 269-271. https://doi.org/10.1046/j.1365-2834.2001.00230.x

Manley, K. (2000). Organisational culture and consultant nurse outcomes: Part 1. Organisational culture. Nursing Standard, May 24-30, 14(36), 34-38. PMID: 11974262

Malterud, K. (2001). Qualitative research: standards, challenges, and guidelines. Lancet, 358, 483-488, August 11. https://doi.org/10.1016/S0140-6736(01)05627-6

Manser, T. (2009). Teamwork and patient safety in dynamic domains of healthcare: a review of the literature. Acta Anaesthesiologica Scandinavica, 53(2), 143-151. https://doi.org/10.1111/j.1399-6576.2008.01717.x

Marcus, J., \& Liberto, L. (2003). Creating accountable, balanced work environment. Nursing Management, 34(10), 25-26. https://doi.org/10.1097/00006247-200310000-00009

Martin, G., Beech, N., MacIntosh, R., \& Bushfield, S. (2015). Potential challenges facing distributed leadership in health care: evidence from the UK National Health Service. Sociology of Health and Illness, 37(1), 14-29. https://doi.org/10.1111/1467-9566.12171

Matei, A., \& Drumasu, C. (2015). Corporate Governance and public sector entities. Procedia Economics and Finance, $4^{\text {th }}$ World Conference on Business, Economics and Management, WCBEM, 26, 495-504.

Maxwell, J. (2013). Qualitative Research Design: An Interactive Approach. London, UK: Sage Publications.

McGuire, E., \& Kennerly, S. (2006). Nurse Managers as Transformational and Transactional Leaders. Nursing Economic, July-August, 24(4), 179-185.

Melnyk, B., Fineout-Overholt, E., Gallagher-Ford, L., \& Kaplan, L. (2012). The State of Evidence-Based Practice in US Nurses. The Journal of Nursing Administration, 42(9), 410-417. https://doi.org/10.1097/NNA.0b013e3182664e0a

Meurer, W., Frederiksen, S., Majersik, J., Zhang, L., Sandretto, A., \& Scott, P. (2007). Qualitative Data Collection and Analysis Methods: The INSTINCT Trial. Academic Emergency Medicine, 14, 1064-1071. https://doi.org/10.1197/j.aem.2007.05.005

Miller, K., Reeves, S., Zwarenstein, M., Beales, J., Kenaszchuk, C., \& Conn, L. (2008). 
Nursing emotion work and interprofessional collaboration in general internal medicine wards: A qualitative study. Journal of Advanced Nursing, 64(4), 332-343. https://doi.org/10.1111/j.1365-2648.2008.04768.x

Miner, M. (2005). Organisational Behaviour. London, UK: ME Sharpe.

Mistovich, J., Hafen, B., \& Karren, K. (2007). Prehospital emergency care. New York, USA: Brady Prentice Hall Health.

Morey, J., Simon, R., Jay, G., Wears, R., Salisbury, M., Dukes, K., \& Berns, S. (2002). Error reduction and performance improvement in the emergency department through formal teamwork training: evaluation results of the MedTeams project. Health Service Research, 37(6), 1553-1581. https://doi.org/10.1111/1475-6773.01104

Morse, J. (2018). Theoretical Coalescence. A Method to Develop Qualitative Theory. Nursing Research, 67(2), 177-187. https://doi.org/10.1097/NNR.0000000000000263

Murphy, L. (2005). Transformational leadership: a cascading chain reaction. Journal of Nursing Management, 13(2), 128-136. https://doi.org/10.1111/j.1365-2934.2005.00458.x

Neely, K. (1997). Editorials: Demand management: the new view of ems?, Prehospital Emergency Care, 1(2), 114-118. https://doi.org/10.1080/10903129708958800

Newhouse, R., Weiner, J., Stanik-Hutt, J., White, K., Johantgen, M., Steinwachs, D., ... Bass, B. (2012). Policy implications for optimizing advanced practice registered nurse use nationally. Policy, Politics \& Nursing Practice, 13(2), 81-89. https://doi.org/10.1177/1527154412456299

O’Brien, J., Martin, D., Heyworth, J., \& Meyer, N. (2008) Negotiating transformational leadership: A key to effective collaboration. Nursing \& Health Sciences, 10(2), 137-143. https://doi.org/10.1111/j.1442-2018.2008.00381.x

O’Higgins, F., Ward, M., \& Nolan, J. (2001). Advanced life support skills undertaken by

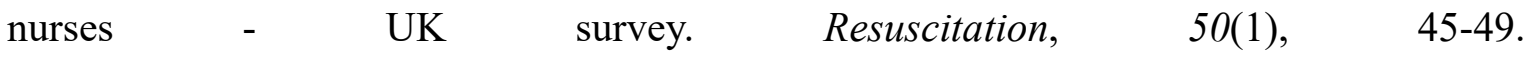
https://doi.org/10.1016/s0300-9572(01)00334-3

Omachonu, V., \& Einspruch, N. (2010). Innovation in Healthcare Delivery Systems: A Conceptual Framework. The Innovation Journal: The Public Sector Innovation Journal, 15(1), article 2 .

Onwuegbuzie, A., \& Leech, N. (2007). Sampling Designs in Qualitative Research: Making the Sampling Process More Public. The Qualitative Report, 12(2), 238-254. Retrieved from https://nsuworks.nova.edu/tqr/vol12/iss $2 / 7$

Orb, A., Eisenhauer, L., \& Wynaden, D. (2001). Ethics in qualitative research. Journal of Nursing Scholarship, 33(1), 93-96. https://doi.org/10.1111/j.1547-5069.2001.00093.x

Pearce, C., \& Sims, H. (2002). Vertical versus shared leadership as predictors of the effectiveness of change management teams: An examination of aversive, directive, transactional, transformational and empowering leader behaviors. Group Dynamics: 
Theory, Research, and Practice, 6(2), 172-197. https://doi.org/10.1037//1089-2699.6.2.172

Pentland, A. (2012). The new science of building great teams. Harvard Business Review, April, 61-70.

Pettigrew, A., Ferlie, E., \& McKee, L. (1992). Shaping strategic change: Making change in large organizations. The case of the National Health Service. London, UK: Sage Publications.

Polit, D., \& Beck, C. (2010). Essentials of Nursing Research-Appraising Evidence for Nursing Practice. Philadelphia, USA: Wolters Kluwer.

Popay, J., Roberts, H., Sowden, A., Petticrew, M., Arai, L., Rodgers, M., ...Duffy, S. (2006). Guidance on the conduct of narrative synthesis in systematic reviews: A product from the ESRC Methods Programme. https://doi.org/10.13140/2.1.1018.4643

Punch, K. (2014). Introduction to Social Research: Quantitative and Qualitative Approaches. London, UK: Sage Publications.

Qu, S., \& Dumay, J. (2011). The qualitative research interview. Qualitative Research in Accounting \& Management, 8(3), 238-264. https://doi.org/10.1108/11766091111162070

Regulatory Agency Consultation. (2005). Medicines and Healthcare products Regulatory Agency Consultation on options for the future of independent prescribing by extended formulary nurse prescribers. MLX 2005:320. Retrieved from http://www.dh.gov.uk/assetRoot/04/10/40/58/04104058.pdf

Reissmann, C. (2008). Narrative methods for the human sciences. London, UK: Sage Publications.

Ritchie, J., \& Lewis, J. (2003). Qualitative Research Practice: A Guide for Social Science Students and Researchers. London, UK: Sage Publications.

Ross, C. (2014). The Benefits of Informal Leadership. Nurse Leader, 12(5), 68-70. https://doi.org/10.1016/j.mnl.2014.01.015

Rubin, H., \& Rubin, I. (2005). Qualitative Interviewing: The Art of Hearing Data. Thousand Oaks, CA, USA: Sage Publications.

Ryan, G., \& Bernard, H. (2003). Techniques to Identify Themes. Field Methods, 15(1), 85-109. https://doi.org/10.1177/1525822X02239569

Sakran, J., Finneman, B., Maxwell, C., Sonnad, S., Sarani, B., Pascual, J., ...Sims, C. (2012). Trauma leadership: Does perception drive reality? Journal of Surgery Education, 69(2), 236-240. https://doi.org/10.1016/j.jsurg.2011.09.004

Sbaraini, A., Carter, S., Evans, R. \& Blinkhorn, A. (2011). How to do a grounded study a worked example of a study of dental practices. BMC Medical Research Methodology, 11, 128. https://doi.org/10.1186/1471-2288-11-128

Schein, E. (1992). Organizational culture and leadership. Jossey-Bass, San Francisco, 
USA.

Seale, C. \& Silverman, D. (1997). Ensuring rigour in qualitative research. European Journal of Public Health, 7(4), 379-384. https://doi.org/10.1093/eurpub/7.4.379

Seidel, J., Henderson, D., Tittle S, Jaffe, D., Spaite, D., Dean, M., ...Maederis, D. (1999). Priorities for research in emergency medical services for children: results of a consensus conference. Journal of Emergency Nursing, 25(1), 12-16. https://doi.org/10.1016/S0099-1767(99)70122-4

Seow, E. (2013). Leading and managing an emergency department - A personal view. Journal of Acute Medicine, 3(3), 61-66. https://doi.org/10.1016/j.jacme.2013.06.001

Schein, E. (2010). Organisational Culture and Leadership. New York, USA: Josey Bass.

Shirey, M. (2006). Authentic Leaders Creating Healthy Work Environments for Nursing Practice. American Journal of Critical Care, 15(3), 256-267. PMID: 16632768

Snilstveit, B. Oliver, S., \& Vojtkova, M. (2012). Narrative approaches to systematic review and synthesis of evidence for international development policy and practice. Journal of Development Effectiveness, 4(3), 409-429, https://doi.org/10.1080/19439342.2012.710641

Snow, J. (2001). Looking beyond nursing for clues to effective leadership. Journal of Nursing Administration, 31(9), 440-443. https://doi.org/10.1097/00005110-200109000-00010

Spanos, A. (1990). Towards a Unifying Methodological Framework. In Modelling Economic Series: Readings in Econometric Methodology. In C. William, \& J. Granger, Readings in Econometric Methodology, Oxford, UK: Clarendon Press.

Stanley, D. (2006a). In command of care: clinical nurse leadership explored. Journal of Research in Nursing, 11(1), 20-39. https://doi.org/10.1177/1744987106059458

Stanley, D. (2006b). Recognising and defining clinical nurse leaders. British Journal of Nursing, 15(2), 108-111. https://doi.org/10.12968/bjon.2006.15.2.20373

Stein-Parbury, J., \& Liaschenko, J. (2007). Understanding collaboration between nurses and physicians as knowledge at work. American Journal of Critical Care, 16(5), 470-477. PMID: 17724244

Stenbacka, C. (2001). Qualitative research requires quality concepts of its own. Management Decision, 39(7), 551-556. https://doi.org/10.1108/EUM0000000005801

Stogdill, R. (1948). Personal factors associated with leadership: A survey of the literature. Journal of Psychology, 25(1), 35-71. https://doi.org/10.1080/00223980.1948.9917362

Strauss, A., \& Corbin, J. (1990). Basics of Qualitative Research: Grounded Theory, Procedures and Techniques. Newbury Park, Chicago, USA: Sage Publications.

Sullivan, E. (2012). Effective Leadership and Management in Nursing. New York, USA: Pearson. 
Sullivan, E., \& Decker, P. (2005). Effective leadership and management in nursing. Upper Saddle River, New Jersey, USA: Pearson Education.

Sutton, J., \& Austin, Z. (2015). Qualitative research: data collection, analysis management. The Canadian Journal of Hospital Pharmacy, 68(3), 226-231. http://dx.doi.org/10.4212/cjhp.v68i3.1456

Tomey, A. (2009). Nursing leadership and management effects work environments. Journal of Advanced Nursing Management, 17(1), 15-25. https://doi.org/10.1111/j.1365-2834.2008.00963.x

Tye, C. (1997). The emergency nurse practitioner role in major accident and emergency departments: professional issues and the research agenda. Journal of Advanced Nursing, 26, 364-370. https://doi.org/10.1046/j.1365-2648.1997.1997026364.x

Villalonga, B. (2000). Privatisation and Efficiency: Differentiating Ownership Effects from Political, Organizational, and Dynamic Effects. Journal of Economic Behaviour and Organisation, 42(1), 43-74. https://doi.org/10.1016/S0167-2681(00)00074-3

Wagner, J., Cummings, G., Smith, D., Olson, J., Anderson, L., \& Warren, S. (2010). The relationship between structural empowerment and psychological empowerment for nurses: a systematic review. Journal of Nursing Management, 18(4), 448-462. https://doi.org/10.1111/j.1365-2834.2010.01088.x

Walsh, S., White, K., \& Young, R. (2008). Over-Connected? A Qualitative Exploration of the Relationship between Australian Youth and Their Mobile Phones. Journal of Adolescence, 31(1), 77-92. https://doi.org/10.1016/j.adolescence.2007.04.004

Ward, P., Rokkas, P., Cenko, C., Pulvirenti, M., Dean, N., Carney, S., ...Meyer, S. (2015). A qualitative study of patient (dis)trust in public and private hospitals: the importance of choice and pragmatic acceptance for trust considerations in South Australia. BMC Health Services Research, 15(1), 297-308. https://doi.org/10.1186/s12913-015-0967-0

Westhues. A., Ochocka, J., Jacobson, N., Simich, L., Maiter, S., Janzen, R., \& Fleras, A. (2008). Developing theory from complexity: reflections on a collaborative mixed method participatory action research study. Qualitative Health Research, 18(5), 701-717. https://doi.org/10.1177/1049732308316531

Wiggins, M., \& Hyrkäs, K. (2011). Achieving excellence in nursing management. Journal of Nursing Management, 19(1), 1-4. https://doi.org/10.1111/j.1365-2834.2010.01226.x

Williams, C., Campbell, S., Henry, K., \& Collier, P. (1994). Variables influencing worker compliance with universal precautions in the emergency department. American Journal of Infectious Control, 22(3), 138-148. https://doi.org/10.1016/0196-6553(94)90002-7

Willis, S., \& Dalrymple, R. (2015). Fundamentals of Paramedic Practice: A Systems Approach (Eds). Chichester, England, UK: John Wiley \& Sons. 
Wilson, B., \& Laschinger, H. (1994). Staff nurse perception of job empowerment and organizational commitment. Journal of Nursing Administration, 24(4-Suppl), 39-47. https://doi.org/10.1097/00005110-199404011-00007

Yuk1, G. (2013). Leadership in organizations. Prentice Hall, Upper Saddle River, NJ, USA.

Yun, S., Faraj, S., \& Sims, H. (2005). Contingent leadership and effectiveness of trauma resuscitation teams. Journal of Applied Psychology, 90(6), 1288-1296. https://doi.org/10.1037/0021-9010.90.6.1288 